January 2017

\title{
Student-led Special Interest Groups as a Model for Inclusion of Specialty Hand Content in OTD Curriculum
}

Nathan Short

Huntington University

Jennifer Bain

Huntington University

Courtney Barker

Huntington University

Zack Bolton

Huntington University

Kristina Dammeyer

Huntington University

See next page for additional authors

Follow this and additional works at: https://encompass.eku.edu/jote

Part of the Curriculum and Instruction Commons, Educational Methods Commons, Higher Education Commons, and the Occupational Therapy Commons

\section{Recommended Citation}

Short, N., Bain, J., Barker, C., Bolton, Z., Dammeyer, K., Fahrney, E., Hale, K., \& Maples, C. (2017). Student-led Special Interest Groups as a Model for Inclusion of Specialty Hand Content in OTD Curriculum. Journal of Occupational Therapy Education, 1 (3). https://doi.org/10.26681/jote.2017.010306 


\title{
Student-led Special Interest Groups as a Model for Inclusion of Specialty Hand Content in OTD Curriculum
}

\begin{abstract}
This article presents a student-led special interest group within a doctorate of occupational therapy (OTD) program as a model to supplement the core curriculum for inclusion of specialty content related to hand therapy. Consisting of advanced educational modules, research article review and discussion, as well as related service projects, the group provides ancillary benefits as well as networking opportunities for student participants. An initial program evaluation demonstrates efficacy as students reported a positive impact on various areas of professional and clinical skills to support specialization in hand therapy upon graduation. The student-driven nature of this experiential learning approach provides more robust content without taxing often limited financial and faculty resources of occupational therapy programs. This model may be generalizable to other areas of occupational therapy practice to provide specialty content for various student interest areas at the academic level, encouraging specialization for new graduates to continue to provide advanced care to diverse populations.
\end{abstract}

\section{Keywords}

Special interest group, hand therapy, curriculum, student-led

\section{Creative Commons License} (c) (1) (9)

This work is licensed under a Creative Commons Attribution-Noncommercial-No Derivative Works 4.0 License.

\section{Acknowledgements}

The authors would like to thank Huntington University and the OTD Program Faculty for supporting the development of the Huntington University Hand Interest Club.

\section{Authors}

Nathan Short, Jennifer Bain, Courtney Barker, Zack Bolton, Kristina Dammeyer, Ethan Fahrney, Kalin Hale, and Carter Maples 


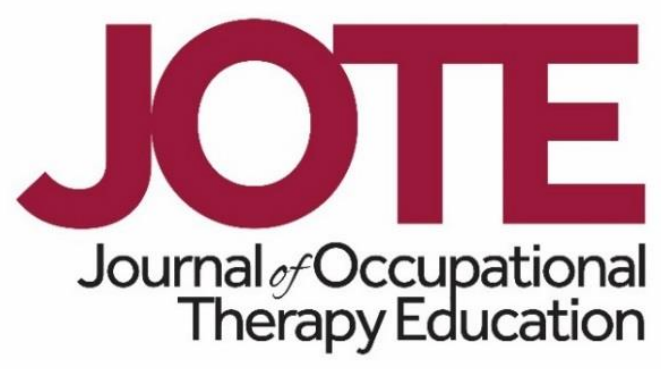

Volume 1, Issue 3

\title{
Student-led Special Interest Groups as a Model for Inclusion of Specialty Hand Content in OTD Curriculum
}

\author{
Nathan Short, OTD, CHT, Jennifer Bain, OTDS, Courtney Barker, OTDS, \\ Zack Bolton, OTDS, Kristina Dammeyer, OTDS, Ethan Fahrney, OTDS, \\ Kalin Hale, OTDS, and Carter Maples, OTDS \\ Huntington University \\ United States
}

\begin{abstract}
This article presents a student-led special interest group within a doctorate of occupational therapy (OTD) program as a model to supplement the core curriculum for inclusion of specialty content related to hand therapy. Consisting of advanced educational modules, research article review and discussion, as well as related service projects, the group provides ancillary benefits as well as networking opportunities for student participants. An initial program evaluation demonstrates efficacy as students reported a positive impact on various areas of professional and clinical skills to support specialization in hand therapy upon graduation. The student-driven nature of this experiential learning approach provides more robust content without taxing often limited financial and faculty resources of occupational therapy programs. This model may be generalizable to other areas of occupational therapy practice to provide specialty content for various student interest areas at the academic level, encouraging specialization for new graduates to continue to provide advanced care to diverse populations.
\end{abstract}

\section{INTRODUCTION}

Academic programs deliver content covering the spectrum of occupational therapy (OT) practice to develop generalist practitioners who may choose to specialize after becoming licensed clinicians. The broad spectrum of practice limits the inclusion of specialty content within the general curriculum and pursuing specialization often requires extensive self-study beyond graduation from an accredited OT program. Students at Huntington University's Occupational Therapy Doctorate (OTD) program recently established a Hand Interest Club to provide an avenue for development of 
advanced knowledge with the goal of early preparation to pursue the Certified Hand Therapist $(\mathrm{CHT})$ credential. A CHT practitioner demonstrates advanced practice in:

"...the art and science of rehabilitation of the upper limb, which includes the hand, wrist, elbow and shoulder girdle. It is a merging of occupational and physical therapy theory and practice that combines comprehensive knowledge of the structure of the upper limb with function and activity... in order to enhance an individual's ability to execute tasks and to participate fully in life situations (Hand Therapy Certification Commission, 2016)."

Rigorous requirements to obtain the CHT credential include a) 4,000 hours of documented direct patient care involving the upper quarter, b) licensure as an occupational or physical therapist for a minimum of three years, as well as c) passing the comprehensive Hand Therapy Certification Exam (HTCE) (Hand Therapy Certification Commission, 2016). Creative avenues for inclusion of advanced hand content and exposure during didactic education may help solidify student interest to maintain a trajectory to certify as a hand therapist upon graduation.

\section{LITERATURE REVIEW}

Incorporation of active learning techniques in graduate and post-graduate programs is gaining momentum. Researchers suggest that student-led programs support independent learning and development of clinical autonomy, which is fundamental in the transition to professional practice and stimulates growth in professional behaviors (Patterson, Flemming, Marshall, \& Ninness, 2017; Smith \& Chenoweth, 2015). Studentled organizations and special interest groups provide a variety of benefits for students including networking and social opportunities, professional experiences, personal development, as well as management and leadership skills (The George Washington University, 2017). Allied health professionals currently maintain various roles within their scope of practice that extend beyond direct clinical practice. Stimulation of deep learning to facilitate the development of these roles may require incorporation of active learning techniques, as provided through student-led initiatives, to supplement traditional methods (Yew et al., 2016).

Students are often passive recipients of information in traditional academic culture, but a paradigm shift may be necessary to maintain effectiveness and quality of higher education in the complex and evolving healthcare arena (Richards, Saddiqui, White, McGuigan, \& Homewood, 2016). Interprofessional collaborative practice (IPCP) and evidence-based practice (EBP) may be fortified by a shift in methods of knowledge translation to graduate students in the allied health fields. IPCP has consistently demonstrated an increase in perceived competence of clinicians to improve patient outcomes (Keller, Eggenberger, Belkowitz, Sarsekeyeva, \& Zito, 2013). However, effective collaboration may be hindered by overlapping scopes of practice, lack of communication, and misunderstood roles of respective disciplines. Findings suggest that opportunities for student-led programs may significantly facilitate advancement in essential interprofessional skills and support the successful transition from classroom to the clinic (Gustafsson et al., 2016). 
Journal clubs have been used as a teaching strategy since the 1800's for healthcare professionals to stay abreast of the latest trends. Evidence suggests that students who participated in journal clubs felt more confident in analyzing and discussing research (Szucs, Benson, \& Haneman, 2017). These clubs encourage self-directed learning which may result in student discovery and incorporation of new research in the field, as well as catalyze meaningful discussions with peers and professionals throughout their academic journey. Integration of student-led special interest groups in OT curricula may foster evidence-based decision-making at the academic level and carryover into future evidence-based clinical practice to ensure quality intervention and positive client outcomes.

Supporting the development of IPCP and EBP may begin as early as the first year of graduate studies through supplemental student-led initiatives, such as a special interest group, that provide little to no burden on program finances and resource management, as member dues provide financing for specific club activities. However, there is a lack of primary research on the direct effects of student-led organizations, particularly in the field of OT. As active learning techniques become more ubiquitous in graduate-level studies and occupational therapy education, there is a critical need for direct assessment of the contribution of these efforts towards educational standards and student outcomes.

Specific to the hand therapy specialty, a recent study identified lack of student knowledge and preparation for student acceptance and success on clinical rotations (Short, Sample, Murphy, Austin, \& Glass, 2017). Hand therapists surveyed recommended advanced preparation in anatomy and upper extremity diagnoses, as well as evaluation and assessment methods as requisite to facilitate success for students in the clinic. Furthermore, professionalism and therapeutic communication were highly prioritized as skill sets to develop before a rotation in a hand therapy setting. These findings served to guide intentional development of specific club objectives and goals for a student-led special interest group to support student success in fieldwork and beyond in future pursuit of hand specialization. The purpose of this article is to present the student-led special interest group as a model for inclusion of advanced hand content and an avenue for development of these recommended clinical and professional skill sets at the academic level to facilitate advanced student learning and the pursuit of specialty clinical practice.

\section{PROGRAM DESCRIPTION AND RELATIONSHIP TO CURRICULUM}

The doctoral mandate for entry-level OT practitioners and evolving accreditation standards demand more in-depth and advanced clinical knowledge, research, and EBP, as well as program and policy development (American Occupational Therapy Association, 2017). Furthermore, the entry-level doctorate requires advanced understanding of theoretical models of occupational theory and application of theory to practice (Accreditation Council for Occupational Therapy Education, 2017). The Hand Interest Club may provide unique opportunities to address these higher learning requirements through advanced educational modules; journal article reviews, discussion, and research collaboration; as well as leadership and program 
development. With these objectives in mind, the Hand Interest Club established a charter with a Vision Statement as follows:

"To further education of upper extremity rehabilitation to promote meaningful occupations. The goal of the hand club is to provide students at the Huntington University Doctorate of Occupational Therapy Program opportunity to gain advanced knowledge and professional experience to pursue the Certified Hand Therapist (CHT) credential."

Membership requirements were established to include a) hand therapy observation hours, b) attendance of $75 \%$ of club meetings, c) relevant seminar or conference attendance, d) research activities, e) service, and f) leadership within the club. Typical organizational leadership positions and an executive committee were also established to set the agenda and guide initiatives. The executive committee collaborated to delineate the roles and duties of each leadership position and outlined the club agenda, including educational modules, service projects, and advocacy. The club advisor, a CHT faculty member, provided administrative support as well as content and logistical guidance to the executive committee which remained the catalyst for club activities and initiatives. The advisor role consisted of consultation on an as-needed basis, facilitation of guest lecturers and other content, and occasional teaching or demonstration during club meetings.

Appropriately, the initial meeting of the club involved the discussion of an article regarding the use of various outcome measures and their alignment with the Occupational Therapy Practice Framework (OTPF; AOTA, 2014; Lesher, Mulcahey, Hershey, Stanton, \& Tiedgen, 2017). Recognizing that hand therapy exists within the broader context of OT, the group explored the overlap and theoretical design of various outcome instruments used in hand therapy in the context of the OTPF. The discussion highlighted the importance of recognizing hand therapy as an occupation-based practice and the necessity of incorporating functional activities as forms of assessment and intervention. The article suggested a critical need for future and current hand therapy practitioners to utilize and continue development of valid outcome measures that support a holistic approach as defined by the OTPF.

In conjunction with review and discussion of relevant journal articles, advanced learning has also taken the form of topical guest lectures, online learning modules, and hands-on demonstrations. Guest lectures have included hand therapists' demonstration of custom orthotic fabrication and a prosthetist demonstrating the latest upper extremity prosthetics. Online educational modules have covered post-operative management of tendon repairs as well as evidence-based scapulothoracic exercises based on electromyography (EMG) studies. Surgical perspectives have also been examined through journal review to promote IPCP. These diverse perspectives supported a holistic view of hand and upper extremity pathologies as well as networking opportunities for students and faculty, integrating the Hand Interest Club within the local therapy community. These connections may serve to provide clinical instructors as well as professional mentors for students pursuing this area of practice. 
The Hand Interest Club, comprised of like-minded and motivated students as well as a faculty advisor, has also served as a "think tank" of sorts to develop scholarly projects and research initiatives. Current research ventures include the exploration of hand content inclusion in OT academic programs, market research for an occupation-based anatomy textbook, as well as the benefits of student-led special interest groups in general as part of the broader context of OT curriculum.

Additionally, doctoral-level accreditation standards call for "active involvement in professional development, leadership, and advocacy" while university-specific student outcomes emphasize professional service through the use of occupation (ACOTE, 2012, p. 3). A recent service project developed and implemented through the Hand Interest Club contributed to these objectives, providing an occupation-based project for a local mental health facility. Renovating an outdoor space at the facility served as a reminder of the functional importance of dexterity for meaningful occupation for student participants. A deck and elevated planter beds were restored, requiring stripping and sanding of wood surfaces, refinishing, and planting a variety of flowers. With subtle but perceptible connection to the roots of occupational therapy, the project also created opportunities for a mental health population to participate in the therapeutic occupation of gardening. Often used as a client-centered activity to engage and give meaning to therapy, gardening requires physical dexterity for manipulation of tools as well as cognition for sequencing and planning, as well as the daily upkeep of the flower beds to keep them nourished and growing.

Club members have also provided pro bono consultation services in collaboration with local therapists and university faculty. Partnering with a local prosthetic company, students provided home and activities of daily living (ADL) modification recommendations for a client who uses body-powered upper extremity prosthetics bilaterally. Applying theory to practice, students gathered an occupational profile for the client, assessed his performance skills, and developed low-technology strategies and tool adaptations to help the client meet his goals related to feeding.

More recently, the club also promoted the establishment of an Advanced Anatomy Work Study program where second-year club members dissected cadavers for the incoming first-year students to use in OTD703: Anatomy \& Kinesiology. The dissection provided more in-depth anatomy knowledge as well as beneficial review for students preparing for clinical rotations within hand therapy where foundational understanding of anatomy and kinesiology are vital to student success. Students from the hand club also served as lab assistants and provided small group tutoring for first year students during the course.

\section{PROGRAM ASSESSMENT}

The Hand Interest Club is a supplement to the core curriculum of Huntington University's OTD program as it is student-led and facilitates advanced, active learning. The club promotes additional, more in-depth knowledge of hand therapy content, building onto the core curriculum. Furthermore, the club aids in professional development, leadership skills, and advocacy. Ancillary benefits include networking with 
local clinicians and guest speakers, obtaining leadership roles within the club, and encouraging students to become active in the community through participation in service projects and volunteering, as well as advocating for the profession of occupational therapy.

With the overall goals of the club in mind, an initial program evaluation was performed with a survey of club participation and membership (Table 1). Club leadership developed the survey based on stated objectives to measure perceived impact of membership and participation. The survey was distributed via email with a SurveyMonkey link to club members including first, second, and third year students who had participated in the club for approximately 6 months. The survey was opened on July $11^{\text {th }}, 2017$ and remained open for 10 days. Survey responses with representative qualitative statements are listed below:

A majority of the students (87\%; $n=13)$, reported an increase in understanding of diagnoses and interventions related to the hand and upper extremity.

"This club has solidified my goals of becoming a future $\mathrm{CHT}$ and helped me better understand and prepare for the process."

In addition, participants $(67 \% ; n=10)$ reported an increased efficacy in therapeutic communication, leadership, and professionalism.

"I have been presented with additional opportunities along with potential collaborations and publications that would most likely not have happened if I wasn't in the club."

Participants (73\%; $n=11)$ also reported an increased likelihood to pursue the CHT specialty after graduation.

"The club has helped me recognize a need for increased hand based knowledge for students interested in pursuing level II fieldworks with CHT's. I have also expanded my knowledge and interest in pursuing a CHT credential in the future". 
Table 1

Initial Program Evaluation Survey Responses ( $\mathrm{n}=15)$

\begin{tabular}{|c|c|c|c|c|c|}
\hline & $\begin{array}{l}\text { Strongly } \\
\text { Agree }\end{array}$ & Agree & Neutral & Disagree & $\begin{array}{l}\text { Strongly } \\
\text { Disagree }\end{array}$ \\
\hline $\begin{array}{l}\text { I feel more confident } \\
\text { with hand-related } \\
\text { content including } \\
\text { clinical application of } \\
\text { the latest evidence- } \\
\text { based research }\end{array}$ & $\begin{array}{c}33.3 \% \\
(n=5)\end{array}$ & $\begin{array}{c}53.3 \% \\
(n=8)\end{array}$ & $\begin{array}{c}13.33 \% \\
(n=2)\end{array}$ & $0 \%$ & $0 \%$ \\
\hline $\begin{array}{l}\text { The depth of my } \\
\text { knowledge of } \\
\text { anatomy, diagnoses, } \\
\text { and interventions } \\
\text { related to the hand } \\
\text { and upper extremity } \\
\text { has increased beyond } \\
\text { knowledge gained in } \\
\text { the general curriculum }\end{array}$ & $\begin{array}{c}26.67 \% \\
(n=4)\end{array}$ & $\begin{array}{c}60.0 \% \\
(n=9)\end{array}$ & $\begin{array}{c}13.33 \% \\
(n=2)\end{array}$ & $0 \%$ & $0 \%$ \\
\hline $\begin{array}{l}\text { I feel my skills as a } \\
\text { professional, including } \\
\text { therapeutic } \\
\text { communication, } \\
\text { leadership, and } \\
\text { professionalism, have } \\
\text { improved as a result of } \\
\text { my participation in the } \\
\text { hand and orthopedic } \\
\text { club }\end{array}$ & $\begin{array}{c}20.0 \% \\
(n=3)\end{array}$ & $\begin{array}{c}46.67 \% \\
(n=7)\end{array}$ & $\begin{array}{c}33.33 \% \\
(n=5)\end{array}$ & $0 \%$ & $0 \%$ \\
\hline $\begin{array}{l}\text { I have a better } \\
\text { understanding of the } \\
\text { process to obtain the } \\
\text { CHT credential and } \\
\text { am more likely to } \\
\text { specialize in this area } \\
\text { of practice after } \\
\text { graduation }\end{array}$ & $\begin{array}{c}60.0 \% \\
(n=9)\end{array}$ & $\begin{array}{c}13.33 \% \\
(n=2)\end{array}$ & $\begin{array}{c}26.67 \% \\
(n=4)\end{array}$ & $0 \%$ & $0 \%$ \\
\hline $\begin{array}{l}\text { I feel more engaged } \\
\text { with the hand therapy } \\
\text { community through } \\
\text { provided resources } \\
\text { ( } \mathbf{n = 1 1} \text { for this item) }\end{array}$ & $\begin{array}{c}45.45 \% \\
(n=5)\end{array}$ & $\begin{array}{c}36.36 \% \\
(n=4)\end{array}$ & $\begin{array}{c}18.18 \% \\
(n=2)\end{array}$ & $0 \%$ & $0 \%$ \\
\hline
\end{tabular}




\section{DISCUSSION}

Although empirical evidence is needed regarding efficacy of student-led initiatives for inclusion of advanced content in OT curriculum, the perceived benefits of this particular endeavor are promising based on student feedback. Results of the survey suggest a majority of the student participants felt more confident with hand-related knowledge, application of the latest evidence-based research, the process of obtaining the $\mathrm{CHT}$ credential, and the connection with the hand therapy community. While perceptions of professional skill development (i.e. therapeutic communication) were not as dramatically impacted, results indicated an overall positive perception, which may serve to guide development of further professional opportunities within the club.

The establishment of the club appears to encourage student engagement in content and skill development during didactic education which may facilitate fieldwork success in hand and upper extremity settings. Furthermore, participation in the club provides a catalyst for pursuit of fieldwork rotations, research, and doctoral experiential projects related to hand therapy. This threading of didactic and experiential content has produced tangible results as many club members have confirmed hand therapy fieldwork rotations at top national sites, used research examining trends within hand therapy as needs assessments for doctoral experiential projects, and collaborated on additional research with faculty guidance.

The average age of the current generation of hand therapists is 48 , with more than 20 years' of experience, according to the most recent practice analysis (Keller et al., 2016), which is an increase from an average age of 42 from the 2008 practice analysis. Research has demonstrated a lack of student preparation for successful clinical rotations in hand settings (Short et al., 2017). Current CHT demographics and identified deficits in student preparation highlight the need for inclusion of content and programming to facilitate students interested in pursuing the hand specialty to meet the needs of this unique and complex client population. Faced with personal and professional demands on time and resources after graduation, club membership may promote a sustained course toward the hand specialty for new graduates.

Beyond specialty content, the club also promotes the development of professional behavior, attitudes, and knowledge. Members of the group reported an increase in confidence and depth of knowledge when discussing hand-related content. Responses to the survey indicated that members also had an increased sense of professionalism as a result of participation. This reflects findings from Smith and Chenoweth (2015): "students who were engaged in co-curricular campus organizations rated themselves on their leadership traits and relational behaviors higher than students who were not involved in these activities" (p. 286). Not specific to hand therapy, potential impact on professional skills may be generalizable to other areas of practice and future roles within healthcare.

Future plans for the group include correlating the club agenda to coincide with first-year curriculum to provide mentorship for incoming students as well as application of knowledge gained in the foundational anatomy and kinesiology course. The club 
leadership is also exploring opportunities to host American Society of Hand Therapy (ASHT) sanctioned educational events, increasing networking opportunities and facilitating student involvement in professional organizations. The initiative thus provides a comprehensive synthesis of knowledge and opportunities to enhance professional and clinical skillsets, supplementing preparation of students for fieldwork rotations in hand therapy settings as well as engaging them at the academic level to maintain their trajectory to specialize.

While the content of this particular endeavor is specific to hand therapy, the format and resources are not, and thus may be generalizable to other areas of specialty practice within occupational therapy. Still in its infancy and development, club genesis required only a few proactive occupational therapy students passionate about the hand therapy specialty and a faculty advisor to provide general oversight and administrative support. These key elements are certainly abundant within occupational therapy education, and this model may be transferable and beneficial for various specialty areas of practice.

\section{Limitations}

Though the initial program evaluation is positive, several key limitations exist. The club is in its infancy and student perceptions are limited in scope, necessitating further empirical inquiry to validate benefits. Moreover, while a prevalent trend of positive perceived impact is evident in the survey results, a contingent of "neutral" responses suggested neither positive nor negative categorical impact for some students. Furthermore, as the stated goal of the club is to facilitate specialization in hand therapy subsequent to licensure, benefits of club participation will not bear tangible fruition for several years. Longitudinal research may provide more insight into the impact of the initiative after graduation and pursuit of specialization.

\section{CONCLUSION}

The student-led special interest group model provides a cost efficient, student-driven, and creative way to supplement core occupational therapy curriculum with specialty content and may be generalizable to occupational therapy education and other specialty areas of practice. Research is needed to further examine the benefits of student-led special interest groups to enhance learning and promote specialty knowledge and skills in occupational therapy.

\section{References}

Accreditation Council for Occupational Therapy Education. (2012). 2011 Accreditation Council for Occupational Therapy Education (ACOTE) Standards. American Journal of Occupational Therapy, 66(6_Supplement), S6-S74. https://doi.org/10.5014/ajot.2012.66S6

American Occupational Therapy Association. (2014).Occupational therapy practice framework: Domain and process (3rd ed.).American Journal of Occupational Therapy, 68(Suppl.1), S1-S48. https://doi.org/10.5014/ajot.2014.682006

American Occupational Therapy Association. (2017). ACOTE 2027 mandate and FAQs. Retrieved from https://www.aota.org/Education-Careers/Accreditation/acotedoctoral-mandate-2027.aspx 
Gustafsson, L., Hutchinson, L., Theodoros, D., Williams, K., Copley, A., Fagan, A., \& Desha, L. (2016). Healthcare students' experiences of an interprofessional, student-led neuro-rehabilitation community-based clinic. Journal of Interprofessional Care, 30(2), 259-261. https://doi.org/10.3109/13561820.2015.1086730

Hand Therapy Certification Commission. (2016). Who is a certified hand therapist (CHT)? Retrieved from https://www.htcc.org/consumer-information/the-chtcredential/who-is-a-cht

Keller, J. L., Caro, C. M., Dimick, M. P., Landrieu, K., Fullenwider, L., \& Walsh M. (2016). Thirty years of hand therapy: The 2014 practice analysis. Journal of Hand Therapy, 29, 222-234. https://doi.org/10.1016/i.jht.2016.02.011

Keller, K. B., Eggenberger, T. L., Belkowitz, J., Sarsekeyeva, M., \& Zito, A. R. (2013). Implementing successful interprofessional communication opportunities in health care education: A qualitative analysis. International Journal of Medical Education, 4, 253-259. https://doi.org/10.5116/ijme.5290.bca6

Lesher, D., Mulcahey, M. J., Hershey, P., Stanton, D., \& Tiedgen, A. (2017). Alignment of outcome instruments used in hand therapy with the Occupational Therapy Practice Framework: Domain and Process and the International Classification of Functioning, Disability and Health: A scoping review. American Journal of Occupational Therapy, 71, 7101190060p1-7101190060p12. https://doi.org/10.5014/ajot.2017.016741

Patterson, F., Fleming, J., Marshall, K., \& Ninness, N. (2017). Student perspectives of a student-led groups program model of professional practice education in a brain injury rehabilitation unit. Australian Occupational Therapy Journal, 1-9. https://doi.org/10.1111/1440-1630.12382

Richards, D., Saddiqui, S., White, F., McGuigan, N., \& Homewood, J. (2016). A theory of change for student-led academic integrity. Quality in Higher Education, 22(3), 242-259. https://doi.org/10.1080/13538322.2016.1265849

Short, N., Sample, S., Murphy, M., Austin, B., \& Glass, J. (2017). Barriers and solutions to fieldwork education in hand therapy. Journal of Hand Therapy, In Press. https://doi.org/10.1016/i.jht.2017.05.013

Smith, L. J. \& Chenoweth, J. D. (2015). The contributions of student organization involvement to students' self-assessment of their leadership traits and relational behavior. American Journal of Business Education, 8(4), 279-288. https://doi.org/10.19030/ajbe.v8i4.9422

Szucs, K., Benson, J., \& Haneman, B. (2017). Using a guided journal club as a teaching strategy to enhance learning skills for evidence-based practice. Occupational Therapy in Healthcare, 31(2) 143-149. https://doi.org/10.1080/07380577.2016.1278296

The George Washington University. (2017). Campus life: Joining clubs and organizations. Retrieved from https://studentengagement.gwu.edu/studentorganizations

Yew, T. M., Dawood, F. K., Narayansany, K. S., Manickam, M. K. P., Jen, L. S., \& Hoay K. C. (2016). Stimulating deep learning using active learning techniques. Malaysian Online Journal of Educational Sciences, 4(3). Retrieved from http://www.moj-es.net/ 